\title{
Língua portuguesa da Base Nacional Comum Curricular (2017): uma análise sob a ótica da Sociolinguística Educacional
}

\author{
Portuguese language in National Curricular Base (2017): The Educational \\ Sociolinguistics point of view
}

\author{
Polyana Zwirtes ${ }^{1}$ \\ Universidade Estadual do Oeste do Paraná \\ Maridelma Laperuta Martins ${ }^{2}$ \\ Universidade Estadual do Oeste do Paraná
}

\begin{abstract}
- RESUMO: O artigo objetiva analisar o componente curricular Língua Portuguesa da BNCC (2017) e aproximações ou afastamentos das práticas de linguagem com a Sociolinguística Educacional. Foram usados como critérios os seis princípios postulados por Bortoni-Ricardo (2005). A metodologia usada foi a análise de conteúdo documental, permitindo a interpretação do pesquisador. Como resultados, observamos que o currículo utiliza termos concernentes à variação linguística, mas o faz de maneira pouco suficiente para o ensino de língua transformador, trata da variação em setores que não refletem criticamente o combate do preconceito linguístico e as avaliações negativas que a variação.
\end{abstract}

- PAlAVRAS-CHAVE: BNCC; Língua Portuguesa; Sociolinguística Educacional.

- ABSTRACT: The article aims analyses the curricular component Portuguese of the National Curriculum Common Base (2017) (Base Nacional Comum Curricular - BNCC, in Portuguese), and approaches or departures from the language practices with Educational Sociolinguistics. The six principles postulated by Bortoni-Ricardo (2005) were used as theoretical criteria. The methodology used was the analysis of the documentary content, allowing the interpretation of the researcher. As results, we observed that the curriculum uses terms related to linguistic variation, but makes it insufficient for the teaching of language to transformation, it deals with variation in sectors that do not take into account reasoning and combating linguistic prejudice and negative estimates of loaded linguistic variation.

- KEYWORDS: National Curriculum Common Base; Portuguese; Educational Sociolinguistics.

\section{Introdução}

A BNCC (2017) é o documento norteador para o currículo da educação básica no Brasil. É a partir da listagem de habilidades e objetivos de aprendizagem da BNCC que estados e municípios devem repensar seus currículos. É em virtude desse caráter

\footnotetext{
${ }^{1}$ Mestre em Ensino pela Universidade Estadual do Oeste do Paraná (2020). Membro do grupo de pesquisa Análise linguística, Ensino e Formação - ALEF - (CAPES/CNPq). Docente das disciplinas de Língua Estrangeira Moderna Inglês e Língua Portuguesa pela Secretaria de Estado de Educação do Paraná SEED/PR.

2 Doutora em Linguística e Língua Portuguesa pela Universidade Estadual Paulista Julio de Mesquita Filho UNESP. Professora adjunto da Universidade Estadual do Oeste do Paraná e Lider e membro do grupo de pesquisa Análise linguística, Ensino e Formação - ALEF - (CAPES/CNPq).
} 
obrigatório do documento que análises e estudos a respeito do que se tem no "novo" currículo se justificam.

Portanto, esta pesquisa debruçou-se sobre o componente de LP dos Anos Finais do Ensino Fundamental com o objetivo de analisar as práticas de linguagem desse componente curricular, verificando aproximações e/ou afastamentos com os princípios da Sociolinguística Educacional $(\mathrm{SE})^{3}$ para o ensino de Português como língua materna, postulados por Bortoni-Ricardo (2005). Assim, a análise limita-se aos textos destinados à Área do Conhecimento Linguagens e aos trechos dedicados à LP, do $6^{\circ}$ ao $9^{\circ}$ ano.

A escolha da SE como fundamentação para a análise ocorre pela concepção de língua enquanto fruto da interação social de sujeitos reais, como representação sociocultural e de identidade de um indivíduo ou grupo. E, também, pela compreensão da língua enquanto resistência e o ensino desta como uma ferramenta de transformação social, de emancipação. Tem-se em Bortoni-Ricardo (2005) a teorização e a fundamentação adotada para essa análise, por isso suas contribuições são presentes ao longo de toda a pesquisa.

A pesquisa tem cunho qualitativo, pois se preocupa com o aprofundamento da compreensão do documento. Quanto aos procedimentos, realizamos uma análise de conteúdo documental, "[...] trata-se de compreender criticamente o sentido manifesto ou oculto das comunicações" (SEVERINO, 2016, p. 129), pois o objeto analisado é um documento oficial, a BNCC. Inicialmente, faremos uma sucinta apresentação dos princípios da SE para, na sequência, apresentar a análise do documento.

\section{Sociolinguística Educacional}

A SE advém de uma preocupação em trabalhar o ensino de língua materna a partir da constatação de língua enquanto variável, pois reflete as vivências e as interações de sujeitos reais. Parte da teoria da Pedagogia Culturalmente Sensível, que prevê situações de agir, falar e interagir semelhantes às existentes na cultura do aluno. A autora Gloria Ladson-Billings (1995) define a Pedagogia Culturalmente Sensível como Pedagogia Culturalmente Relevante; e, em suas palavras, essa prática pode ser entendida como uma pedagogia:

[...] comprometida com o empoderamento coletivo, e não apenas individual. A pedagogia culturalmente relevante baseia-se em três critérios ou proposições: (a) os estudantes devem ter sucesso acadêmico; (b) os estudantes devem desenvolver e/ou manter competência cultural; e (c) os estudantes devem desenvolver uma consciência crítica através da qual desafiam o status quo da atual ordem social. (LADSON-BILLINGS, 1995, p. 159, tradução livre).

Em entrevista publicada no Brasil, Ladson-Billings (apud GANDIN et al. 2002, p. 281-284) apresenta essas três proposições como alicerces, que não têm relações hierárquicas entre si, mas que atuam igualmente. O primeiro deles, o desempenho escolar, não se limita a incutir informações nas crianças, mas a ajudá-las a desenvolver análises críticas a respeito do que estão aprendendo. É preciso ensinar as crianças a terem o controle do próprio aprendizado e buscarem aquilo que julgam importante.

Já o segundo item dessa tríade é chamado de competência cultural. Refere-se à capacidade de as crianças compreenderem quem elas são, de onde vêm e por que determinadas conteúdos são importantes para suas aprendizagens; refere-se a questões

\footnotetext{
${ }^{3}$ Adotamos SE para Sociolinguística Educacional.
} 
históricas que são negligenciadas ou até desconhecidas, questões de lutas sociais e políticas dos grupos a que essas crianças pertencem.

O terceiro, igualmente importante, trata da consciência sociopolítica. Influenciado por Paulo Freire, esse alicerce destina-se à conscientização sociopolítica das crianças e à compreensão de que o que estudam e aprendem na escola tem um objetivo social maior. Essa consciência deve ultrapassar as paredes da sala de aula. O olhar não pode se limitar apenas ao próprio desempenho escolar. É preciso que as crianças compreendam o todo e consigam refletir pensando na coletividade e num bem maior e mais abrangente.

Essa estratégia de ensino, segundo Bortoni-Ricardo (2005, p. 142), seria uma facilitadora do processo de ensino, pois ativaria no aluno questões sociais que lhes são familiares e introduziria novos saberes de maneira contextualizada e confortável. A adoção dessa proposta de trabalho, para o ensino de língua, minimizaria os estigmas da variação linguística dentro do ambiente escolar e da sala de aula e oportunizaria a aprendizagem e o domínio do letramento adequado às diferentes situações de comunicação sem coibir os alunos que porventura advém de uma sociedade cujos padrões linguísticos não correspondem aos de prestígio social.

A Pedagogia Culturalmente Sensível se apresenta como uma proposta de diminuição dos problemas sucedidos do uso do português popular no ambiente escolar que, em muitos casos, é alvo de discriminação e desvalorização, e são nesses pontos que a teoria corrobora e permeia os pressupostos do ensino de língua a partir da SE.

Bortoni-Ricardo (2005) discute a valorização de um "falar bem" o português brasileiro, originado por uma classe de pessoas falantes da variedade de prestígio. Também apresenta a escola como uma perpetuadora dessa valorização. A escola faz do ensino sistemático de língua algo impositivo, pois toda variação que foge à língua da cultura dominante é defeituosa e deve ser eliminada, perpetuando uma variedade sobre outras (BORTONI-RICARDO, 2005, p. 14).

Esses fatos, além de reforçarem o estereótipo de uma variedade linguística e concedê-la maior prestígio sobre outras, trazem dois graves problemas para a escolarização: os alunos não são respeitados quanto às suas variantes de origem e não lhes é ensinada de forma eficiente a variedade prestigiada ou a norma-padrão (BORTONI-RICARDO, 2005).

Assim, a autora afirma que é tarefa da SE “contribuir para o desenvolvimento de uma pedagogia sensível às diferenças sociolinguísticas e culturais" (BORTONIRICARDO, 2005, p. 130). E postula seis princípios fundamentais para a SE (BORTONI-RICARDO, 2005, p. 130-133), utilizados como critérios de análise e interpretação dos dados:

i. A influência da escola deve ser nos estilos mais formais e monitorados da língua, pois o vernáculo coloquial é inerente aos saberes dos alunos. Qualquer falante, por mais escolarizado que seja, em momentos de descontração e informalidade, utilizase de variantes do seu dialeto de origem. No entanto, a escola deve cumprir o papel de instruir e dar condições para que esse mesmo falante possa utilizar a língua também em situações formais e de maior monitoramento.

ii. Variantes que não acarretam uma avaliação negativa na fala não precisam ser alvo de preocupação da escola. Existem quebras de regras normativas que não causam ruídos ou estranheza ao serem empregadas em situações monitoradas de uso da língua, portanto a escola deve se debruçar sobre aquelas que carregam uma avaliação negativa. 
iii. A inserção da variação sociolinguística na matriz social. É fato que, no Brasil, a variação linguística é resultante da má distribuição de bens culturais, portanto, são comuns expectativas altas ou baixas em relação aos alunos advindos de classes sociais distintas. Assim, as crenças e o conhecimento de professores interferem no processo de fortalecimento destes estereótipos ou de mudança e oportunidade de mobilidade social através da língua.

iv. A diferenciação do uso da língua para eventos de letramento em sala de aula e eventos de oralidade, assim não se valeriam da classificação de português culto e português ruim, mas de uma dicotomia entre letramento e oralidade.

v. A descrição da variedade na Sociolinguística deve estar associada à análise etnográfica e interpretativa da sala de aula. Em cada sala, há uma variação e uma valoração diferente. Alguns ambientes e professores entendem a variação como algo de menor prestígio, outros como uma naturalidade da língua, o que implica em comportamentos e resultados distantes na aprendizagem.

vi. O processo de conscientização crítica dos professores e alunos quanto às implicações sociais e as desigualdades que as variações refletem. Fazer com que os envolvidos no processo percebam de onde as variações vêm, quais cargas valorativas implicam e, consequentemente, repensem e reflitam sobre o agir docente.

Sobre o sexto item, em específico, encontramos que trabalhos de conscientização de professores e alunos são possíveis, e os resultados se mostram positivos, como a pesquisa realizada por Laperuta-Martins (2014) com a confirmação da hipótese de que o preconceito linguístico, estritamente ligado ao preconceito social, pode ser atenuado com a realização de trabalhos de conscientização sobre a Teoria Sociolinguística.

Por conseguinte, propostas para uma educação sociolinguística devem existir na sala de aula, visto que o objetivo do ensino de língua materna deve ser o de habilitar o aluno a interpretar situações de uso da língua nos mais diversos contextos e não de (d)escrever regras e normas.

No entanto, práticas de ensino de língua por um viés sociolinguístico só são possíveis se for de interesse da escola e, principalmente, daqueles que a mantém. É necessária uma visão de educação para a promoção da igualdade e da democracia, que não vise à perpetuação de uma classe sobre outra e que pretenda, de fato, oportunizar o conhecimento e condições semelhantes a todos os alunos que nela estiverem permitindo que se apropriem da língua e que façam dela uma ferramenta de transformação, pois "o caminho para uma democracia é a distribuição justa de bens culturais, entre os quais a língua é o mais importante" (BORTONI-RICARDO, 2005, p.15).

Dessa forma, é partindo dos pressupostos postulados para uma educação sob a perspectiva da SE, que a análise do componente curricular de LP na BNCC se baseia. A partir deste ponto, procedemos a uma análise de conteúdo do documento, que pretende tornar inteligível suas entrelinhas sobre esse ensino.

\section{O Componente Curricular Língua Portuguesa na BNCC (2017)}

Antes da análise pormenorizada dos trechos da BNCC, é mister salientar que o currículo cumpre papel primordial na organização da escola. É preciso compreender que o currículo envolve questões além de uma proposta de conteúdos, mas todo e qualquer fenômeno educacional. 
A escolha de alguns conteúdos em detrimento de outros na construção de um currículo é um exercício de poder que tem implicações para além da sala de aula, para a organização social, para a manutenção ou a transformação de todo um sistema, pois o conhecimento recebe significações distintas de acordo com a vertente de currículo a que está submetido (LOPES \& MACEDO, 2011).

Partindo para a análise específica do componente curricular de LP, temos, no texto "A área de linguagens", a compreensão de linguagem, seja ela corporal, verbal, visual, sonora ou digital, como mediadora de atividades e práticas sociais desempenhadas por sujeitos sociais. Outrossim, o texto afirma que os estudantes devem compreender "que as linguagens são dinâmicas, e que todos participam desse processo de constante transformação" (BRASIL, 2017, p. 63). Considerações que, em princípio, corroboram com a concepção de língua como instrumento de interação, apresentada anteriormente e com as concepções de língua defendidas pela Sociolinguística.

No entanto, apesar de tratar da dinamicidade da língua falada por sujeitos reais e apresentar as diferentes linguagens: corporais, linguísticas, midiáticas, visuais e sonoras, as "Competências específicas de linguagens para o Ensino Fundamental" não apresentam as variações linguísticas. $\mathrm{O}$ que mais se aproxima dos preceitos colocados pela SE é a competência 3, que aborda o uso das diferentes linguagens em diferentes contextos. Mas o faz remetendo às linguagens visual, sonora, corporal, linguística e digital para o compartilhamento de informações e o estabelecimento de diálogos que possam promover a resolução de conflitos e a cooperação. Nota-se que a preocupação está em apresentar as diferentes formas de linguagens existentes, não restringindo a área à língua escrita ou falada, mas a linguagem gestual, corporal, sonora.

No item destinado à "Língua Portuguesa", a BNCC aborda que, para o desenvolvimento de capacidades de leitura, produção e tratamento das informações são necessários conhecimentos sobre os gêneros, os textos, a língua, a norma-padrão e as diferentes linguagens (semioses). Até esse item, o texto não trata da necessidade de compreender as variações linguísticas a fim de conhecê-las, valorizá-las e de combater o preconceito linguístico. E quando menciona o tema, o faz misturando aspectos de variação linguística com de preservação linguística das diferentes línguas existentes no Brasil, traz questões de língua indígena ou de imigração, como no trecho:

\begin{abstract}
Ainda em relação à diversidade cultural, cabe dizer que se estima que mais de 250 línguas são faladas no país - indígenas, de imigração, de sinais, crioulas e afro-brasileiras, além do português e de suas variedades [...]. Assim, é relevante no espaço escolar conhecer e valorizar as realidades nacionais e internacionais da diversidade linguística e analisar diferentes situações e atitudes humanas implicadas nos usos linguísticos, como o preconceito linguístico. (BRASIL, 2017, p. 70).
\end{abstract}

Ou seja, aborda as variedades linguísticas e o preconceito linguístico, mas configura-o como uma questão de política linguística de preservação de línguas indígenas, crioulas ou de imigração. Trata como variedade linguística particularidades de comunidades linguísticas, desconsiderando questões de variação linguística que não compreendem delimitações geográficas ou culturais, como as relacionadas a questões sociais, etárias, econômicas.

Questões de valorização de diferentes línguas no território brasileiro são relevantes e devem ser contempladas no currículo. Porém no Brasil, a estratificação linguística não acontece, majoritariamente, em função de fronteiras étnicas ou raciais, exceto em uma minoria de comunidades bilíngues, mas "é o resultado da secular desigualdade na distribuição de renda e, consequentemente, na distribuição de bens 
culturais, entre os quais assuma maior relevo a própria escolarização" (BORTONIRICARDO \& DETTONI, 2001, p. 82).

Mais à frente, o texto explicita como são organizados os conteúdos. Os eixos do componente de LP compreendem a: oralidade, leitura/escuta, produção e análise linguística/semiótica (BRASIL, 2017, p. 71), vejamos cada um deles:

Ao descrever a prática de linguagem análise linguística/semiótica, o texto reforça a ideia de que os conhecimentos linguísticos são de caráter estruturalista, utilizando de termos como sistema e norma, para explicitar quais os conhecimentos linguísticos englobados no currículo. Tende a aproximar-se da concepção de linguagem enquanto instrumento de comunicação, compreendida como um código.

O Eixo Leitura apresentado na BNCC engloba textos escritos, orais e multissemióticos. E compreende a leitura para fruição estética de textos e literatura, para embasar trabalhos escolares, para conhecimento, discussão e debates sobre temas sociais, para sustentar reivindicações e ter conhecimentos que permitam o desenvolvimento de projetos pessoais (BRASIL, 2017, p. 71). Aborda uma diversidade gêneros para as práticas de leitura, porém não menciona as variedades linguísticas em nenhum momento. Não apresenta considerações pertinentes ao tratamento da variação ou quaisquer outros tópicos relacionados aos preceitos da SE.

Em um dado momento, realça a importância em considerar a diversidade cultural, "de maneira a abranger produções e formas de expressão diversas [...] de forma a garantir ampliação de repertório, além de interação e trato com o diferente" (BRASIL, 2017, p. 75). O que pode, de algum modo, abrir interpretação para o trabalho de leitura voltado para as variedades linguísticas. Mas de maneira superficial e pouco suficiente, o texto trata mais de divergências culturais em sua totalidade e não de questões especificadamente sociolinguísticas.

O Eixo da Produção de Textos refere-se à interação e à autoria de textos, sejam eles orais, escritos ou multissemióticos, todavia, o tratamento do uso da língua descrito nas habilidades a serem desenvolvidas englobam práticas de adaptação do discurso/gênero em diferentes contextos, apenas, e não da língua em uso, variável, como real e possível ou não estigmatizada. Tanto o é que, em um dos tópicos, denominado Estratégias de Produção (BRASIL, 2017, p. 78), os termos empregados - revisão, edição, reescrita, adequação - podem levar o currículo à seguinte interpretação: as variedades linguísticas são trazidas para a sala de aula, no entanto para a sua correção, a fim de que seja corrigida, apagada e evitada. A variação é estigmatizada, pois "a escola é norteada para ensinar a língua da cultura dominante" (BORTONI-RICARDO, 2005, p. 14).

No Eixo Oralidade, as práticas destinam-se às produções orais, sejam elas face a face ou não. Trata da reflexão das diferenças em termos formais, estilísticos e linguísticos. Somente no subitem denominado Relação entre fala e escrita é que a variedade linguística se apresenta, no tópico: "Refletir sobre as variedades linguísticas, adequando sua produção a esse contexto" (BRASIL, 2017, p. 80). Ou seja, o estudante deve desenvolver a habilidade de refletir sobre as variedades, como se fossem presentes apenas no continuum letramento (BORTONI-RICARDO, 2005), na diferença do texto oral para o texto escrito ou na adequação do discurso oral para o escrito (e vice-versa).

Trata-se de um fato bastante conhecido: a variedade quando trazida para a sala de aula tange questões regionais ou as adaptações da língua nos estilos orais e escritos. Novamente, a variedade não faz parte de uma reflexão que leve à conscientização da pluralidade de falares, a repensar práticas excludentes, estigmas e preconceitos linguísticos. Ademais, ao observar as menções a variedades linguísticas, essas sempre 
estão acompanhadas de ações que remetem à reflexão e à adequação; não a reflexão para a compreensão e valorização.

No Eixo da Análise Linguística/Semiótica a variação linguística tem maior destaque, se comparado aos outros eixos. Num primeiro momento, a variação está voltada para as práticas de oralidade, pois ao relatar que este eixo compreende procedimentos e estratégias (meta)cognitivas de análise e avaliação consciente das materialidades do texto, o documento menciona que:

No caso de textos orais [... ]. No que tange ao estilo, serão levadas em conta as escolhas de léxico e de variedade linguística ou estilização e alguns mecanismos sintáticos e morfológicos (BRASIL, 2017, p. 80).

Ou seja, o fenômeno da variação linguística está relacionado às implicações da oralidade, não da escrita. Entretanto, o documento situa a variação linguística, assim como as escolhas lexicais e morfológicas, como necessários para a compreensão e a produção de linguagens e em construção ao longo de toda a etapa do Ensino Fundamental (BRASIL, 2017, p. 81). Cabe então, desvendar, ao longo da análise das habilidades específicas de cada ano escolar, como são tratadas as questões de variação linguística na BNCC. Em um parágrafo, neste mesmo eixo, é possível encontrar menção ao estudo da variação enquanto ferramenta de valorização e combate ao preconceito linguístico, vejamos:

Cabem também reflexões sobre os fenômenos da mudança linguística e da variação linguística, inerentes a qualquer sistema linguístico, e que podem ser observados em quaisquer níveis de análise. Em especial, as variedades linguísticas devem ser objeto de reflexão e o valor social atribuído às variedades de prestígio e às variedades estigmatizadas, que está relacionado a preconceitos sociais, deve ser tematizado (BRASIL, 2017, p. 81).

E também, no quadro de habilidades do componente, se destaca a existência de um tópico destinado à variação linguística, como ilustrado abaixo:

Figura 1 - Tópico destinado a Variação Linguística (BRASIL, 2017, p. 83

Variação linguística

- Conhecer algumas das variedades linguísticas do português do Brasil e suas diferenças fonológicas, prosódicas, lexicais e sintáticas, avaliando seus efeitos semânticos.

- Discutir, no fenômeno da variação linguística, variedades prestigiadas e estigmatizadas e o preconceito linguístico que as cerca, questionando suas bases de maneira crítica.

Nesses trechos, observa-se que o documento aponta para alguns dos preceitos defendidos pela SE para o currículo. O tópico apresenta as necessidades de conhecer a variação linguística para a compreensão da sua naturalidade e inerência e da discussão e reflexão das variedades prestigiadas versus estigmatizadas, como indispensáveis para o combate às violências simbólicas e ao preconceito linguístico.

$\mathrm{Na}$ sequência, o documento explica que todos os eixos estão relacionados a uma outra categoria/divisão: os campos de atuação; e estes justificam-se na contextualização, para que essas práticas tenham relação com situações da vida social e sejam situadas em contextos significativos para os estudantes. (BRASIL, 2017, p. 85).

$\mathrm{O}$ excerto seguinte, a ser analisado, é intitulado "Competências específicas de Língua Portuguesa para o Ensino Fundamental". Composto por dez competências a 
serem desenvolvidas nos estudantes. O texto abrange a língua em seu caráter histórico, social, variável e heterogêneo, em conformidade com as concepções de língua defendida pela SE.

$\mathrm{Na}$ competência 4, tem-se o discurso voltado para as questões da variação e do combate ao preconceito linguístico, pois espera que o aluno possa: "4. Compreender o fenômeno da variação linguística, demonstrando atitude respeitosa diante de variedades linguísticas e rejeitando preconceitos linguísticos" (BRASIL, 2017, p. 87). Confirmando algumas das proposições explicitadas nos eixos e nas práticas de linguagens.

Ao realizar a leitura de todo o documento, constata-se que há avanços no que diz respeito ao ensino de leitura, oralidade e produção de textos, que a preocupação com o uso efetivo da língua tem avançado no currículo, mas que as questões da variação linguística e do preconceito linguístico são postas em parágrafos que mais parecem desconectados do todo. A variação e todas as suas implicações são resumidas a algumas linhas, sem contextualização ou reflexão do que representam, sem considerar a carga de divisão e exclusão que a língua concebe em determinados contextos, sem buscar uma quebra do olhar estigmatizado sobre particularidades linguísticas.

É necessário que, além de menções à existência da variação linguística, o ensino de língua desenvolva "crítica aos preconceitos linguísticos (que estão ainda tão arraigados entre nós no Brasil), estimulando práticas positivas diante das diferenças e contribuindo assim para a reconstrução do nosso imaginário nacional sobre a língua" (FARACO, 2008, p. 162).

Por fim, o último tópico a ser analisado: "Língua Portuguesa no Ensino Fundamental - Anos Finais: Práticas de linguagem, objetos de conhecimento $e$ habilidades". É organizado com um texto inicial e tabelas que especificam as habilidades a serem desenvolvidas em cada ano escolar. Nota-se que a gramática normativa tem posição de destaque, pois antes de introduzir os conteúdos subdivididos por ano escolar, o currículo assume que os objetivos de aprendizagem:

\footnotetext{
“[...] sobretudo aqueles que dizem respeito à norma, são transversais a toda a base de Língua Portuguesa. O conhecimento da ortografia, da pontuação, da acentuação, por exemplo, deve estar presente ao longo de toda escolaridade, abordados conforme o ano da escolaridade" (BRASIL, 2017, p. 139, grifo nosso).
}

Ou seja, os objetivos se aplicam em todas as etapas e anos escolares, mas os que dizem respeito à norma se sobressaem aos demais. $\mathrm{O}$ que reforça a ideia, equivocada, de que o ensino de LP pautado no ensino da gramática é um ensino de qualidade; corrobora as suposições de que só se ensina português quando se ensina a regra.

As tabelas de práticas de linguagem, objetos de conhecimento e habilidades encontram-se dividida por blocos: um com conteúdos do $6^{\circ}$ ao $9^{\circ}$ ano, outro do $6^{\circ}$ e $7^{\circ}$ ano e o terceiro do $8^{\circ}$ e $9^{\circ}$ ano. Não há um arranjo de conteúdos para cada série, mas para cada par de ano escolar.

Analisando cada uma das habilidades, é possível encontrar exemplos de gêneros que podem ser utilizados em cada campo de atuação, e também questões que competem à variação linguística. A primeira delas encontra-se na habilidade "EF69LP07", enquadrada na produção de textos do Campo Jornalístico-Midiático, no objeto de conhecimento nominado "textualização": 
Produzir textos em diferentes gêneros, considerando sua adequação [...] variedade linguística e/ou semiótica apropriada a esse contexto [...], utilizando estratégias de planejamento, elaboração, revisão, edição, reescrita/redesign e avaliação de textos, para, com a ajuda do professor e a colaboração dos colegas, corrigir e aprimorar as produções realizadas, fazendo cortes, acréscimos, reformulações, correções de concordância, ortografia, pontuação em textos [... ]. (BRASIL, 2017, p. 143, grifos nossos).

O currículo quer uma produção textual que seja adequada à variedade linguística e à construção da textualidade, para que, com o auxílio do professor e dos colegas, esse texto seja aprimorado, com correção de concordância, ortografia, pontuação.

De fato, é papel da escola e do professor de LP, promover a escrita para atender às necessidades reais do uso da língua, permitir a compreensão e uso das formas mais estilizadas do português e apropriar-se da norma, mas o que se observa ao longo da BNCC é o jogo de colocação das variedades linguísticas para a correção. Ora, ao utilizar o termo corrigir tem-se a noção de errado e certo no uso da língua e esse erro está vinculado às variedades linguísticas, como pode se observar em outra habilidade: "(EF09LP04) Escrever textos corretamente, de acordo com a norma-padrão, com estruturas sintáticas complexas no nível da oração e do período" (BRASIL, 2017, p. 187).

Nessa habilidade é perceptível a concepção de erro do currículo, aquilo que foge a norma-padrão não é considerado correto, portanto errado está. Em outra habilidade também se tem essa confirmação:

(EF69LO08) Revisar/editar o texto produzido - notícia, reportagem, resenha, artigo de opinião, dentre outros -, tendo em vista sua adequação ao contexto de produção, a mídia em questão, características do gênero, aspectos relativos à textualidade, a relação entre as diferentes semioses, a formatação e uso adequado das ferramentas de edição (de texto, foto, áudio e vídeo, dependendo do caso) e adequação à norma culta (BRASIL, 2017, p. 143, grifos nossos).

A revisão do texto deve acontecer para além da adequação aos contextos de produção, para adequação à norma culta. Outrossim, o adjetivo "culta" atribuído à norma, no documento, merece uma observação. Os diferentes termos utilizados para falar de norma são alvos de debate. Já há alguns anos, Faraco (2008), em tom crítico, usa o termo "norma curta", pois este reforça uma hierarquização social existente entre as variedades linguísticas e as "diversas normas", uma vez que o posicionamento social privilegiado dos falantes da "norma culta" os faz tê-la como a melhor em confronto com as muitas outras normas, além de incorrer que os falantes não pertencentes a esse grupo são "incultos". O documento deveria, então, utilizar do termo "norma-padrão", que remete à prescrição, àquilo que se tem como ideal de uso da língua, que está acima do uso real dos falantes, "a língua oficial de um Estado" (BAGNO, 2017).

Mais à frente, as questões pertinentes à variedade linguística reaparecem no Campo Artístico-Literário, nas práticas de Leitura, sob a habilidade EF69LP47:

Analisar, em textos narrativos ficcionais [... ] os efeitos de sentido decorrentes dos tempos verbais, dos tipos de discurso, dos verbos de enunciação e das variedades linguísticas (no discurso direto, se houver) empregados [...] (BRASIL, 2017, p. 159, grifo nosso).

O currículo deseja que o aluno analise os elementos que compõem o texto literário para a sua compreensão e caracterização, incluindo os cenários descritos, as

Traços de Linguagem, Cáceres, v. 4, n. 2, p. 51-63, 2020. 
personagens e as variedades linguísticas, quando presentes no discurso direto. As variedades linguísticas são tomadas como presentes apenas na oralidade, pois aparecem na prática de Leitura, mas na leitura de um trecho que transcreve a fala. Como se as mudanças linguísticas ocorressem apenas no âmbito da fala, e não na escrita.

$\mathrm{Na}$ mesma página, a ideia de variedade linguística enquanto fenômeno da oralidade se confirma em duas outras habilidades. A primeira, EF69LP50, dedica-se à elaboração de textos teatrais e guia o aluno a explicitar "as marcas de variação linguística (dialetos, registros e jargões)" (BRASIL, 2017, p. 159). Ou seja, está inserida em um gênero que se utiliza da oralidade e não apenas da escrita. A segunda, EF69LP52, já se enquadra na prática de linguagem destinada à oralidade e tem em seu texto:

Representar cenas ou textos dramáticos, considerando, na caracterização dos personagens, os aspectos linguísticos e paralinguísticos das falas (timbre e tom de voz, pausas e hesitações, entonação e expressividade, variedades e registros linguísticos [...] (BRASIL, 2017, p. 159).

A variedade é vista como característica da oralidade, presente apenas na fala dos sujeitos. Quando abordada no campo da leitura ou da escrita, a variedade aparece em textos com discursos diretos, com a transcrição ou com a leitura da fala de personagens. Ou seja, mesmo que no campo do texto escrito a variedade é colocada em situações onde a escrita está representando a oralidade, como se a variação não ocorrer na escrita pela escrita.

O último item do bloco de habilidades destinado do $6^{\circ}$ ao $9^{\circ}$ ano traz como objeto de conhecimento a variação linguística, dentro da prática de linguagem: análise linguística/semiótica para todos os campos de atuação: "(EF69LP55) Reconhecer as variedades da língua falada, o conceito de norma-padrão e o de preconceito linguístico" e "(EF69LP56) Fazer uso consciente e reflexivo de regras e normas da norma-padrão em situações de fala e escrita nas quais ela deve ser usada" (BRASIL, 2017, p. 161).

Em princípio, por estar em uma área destinada a todos os campos de atuação e aos quatro anos escolares, com o título "variações linguísticas" como objeto de conhecimento, o currículo parece compreender os princípios de um ensino de língua pautado na SE. No entanto, na primeira habilidade encontram-se dois problemas: o aluno deve reconhecer as variedades da língua falada - mais uma vez, a variação não está ligada às práticas de escrita e leitura; e o aluno deve reconhecer os conceitos de norma-padrão e preconceito linguístico, mas não os conhecer para a reflexão, crítica ou até mesmo combate ao preconceito. Não são propostas práticas que façam os alunos perceberem de onde as variações vem, quais as cargas valorativas que implicam, quais os estigmas que carregam; são colocadas práticas de reconhecimento de termos e conceitos sem reflexão e ação.

$\mathrm{Na}$ segunda habilidade, temos uma preocupação com o uso da norma-padrão e não com as variações linguísticas. A norma-padrão é reforçada, dentro da fala e da escrita e o aluno deve fazer uso consciente e reflexivo dela em situações em que deva ser empregada. Não há qualquer menção às variações linguísticas.

$\mathrm{O}$ item parece ser colocado no currículo como forma de "cumprimento de uma exigência", que desconhece (ou não quer conhecer) as reais implicações de um ensino pautado na SE, que não concebe (ou não quer conceber) as questões de reflexão sobre as variações linguísticas como indispensáveis para uma educação que promova a igualdade, o sentimento de pertencimento do aluno, para uma proposta sensível.

No bloco destinado, especificamente, ao $6^{\circ}$ e $7^{\circ}$ ano, não há menção às variedades linguísticas. Apenas as que foram expostas anteriormente como habilidades 
destinadas a todos os anos escolares. Somente no bloco destinado ao $8^{\circ}$ e $9^{\circ}$ ano é que habilidades destinadas ao trato da variação reaparecem.

Habilidades que se enquadram em todos os campos de atuação e dentro das práticas de analise linguística/semiótica, estão colocadas da seguinte forma: "(EF09LP07) Comparar o uso de regência verbal e regência nominal na norma-padrão com seu uso no português brasileiro coloquial oral" e "(EF09LP10) Comparar as regras de colocação pronominal na norma-padrão com o seu uso no português brasileiro coloquial" (BRASIL, 2017, p. 189 e 191).

Ambas as habilidades tratam da comparação entre o uso coloquial/oral da língua com a norma-padrão, aspectos importantes e pertinentes para o conhecimento de questões linguísticas reais e de uso. Possibilidades que permitem ao docente levar a reflexão e a observação das falhas constantes da norma-padrão, na sua impossibilidade de abranger todas as formas de uso possíveis da língua. No entanto, tal reflexão pode se dar por interesse do docente, não por indicação do próprio currículo.

Promove a comparação entre a norma-padrão e a variação, mas não promove a reflexão sobre isso, sobre as disparidades de exigência de um português estilizado em diferentes esferas, das disparidades sociais que representam a comparação entre essas variações e a norma-padrão.

A última habilidade constatada no currículo de LP também se destina ao tratamento da variação linguística, elencada apenas ao $9^{\circ}$ ano do Ensino Fundamental: "(EF09LP12) Identificar estrangeirismos, caracterizando-os segundo a conservação, ou não, de sua forma gráfica de origem, avaliando a pertinência, ou não, de seu uso" (BRASIL, 2017, p.191). Trata da variação linguística e dos estrangeirismos, da incorporação de palavras de outras línguas para o português e do aportuguesamento ou não das palavras de acordo com o contexto, o que pode tangenciar questões de conservação e valorização do português.

Ao retomar os seis princípios para um ensino de LP a partir da SE, postulados por Bortoni-Ricardo (2005), temos poucas aproximações e muitos afastamentos com o currículo proposto pela BNCC:

O primeiro princípio trata da influência da escola na aquisição de repertórios linguísticos necessários para os estilos mais monitorados. De fato, a BNCC propõe estudo da língua em situações reais do cotidiano e que exigem do aluno diferentes adequações e monitoramento linguísticos. Nas práticas de leitura e produção de textos, os gêneros propostos e as intenções parecem estar de acordo com esse princípio.

O princípio dois afirma que as variações que não trazem uma avaliação negativa na sociedade não são objetos de correção da escola. No entanto, ao comparar a colocação pronominal e a regência verbal presente na norma-padrão e o uso coloquial, a escola faz o oposto do esperado. Analisa, por meio de pesquisa e comparação, questões que não carregam estigmas aos seus usuários e pode acabar deixando pormenorizado ou esquecidas questões carregadas de estigma e preconceito linguístico.

Exemplo disso, é a regência do verbo "assistir" (ontem, assisti ao filme), que não é mais "exigida socialmente" em gêneros orais ou escritos, seja em estilos menos ou mais monitorados; ou a colocação pronominal de ênclise, que não pertence ao português brasileiro e não gera estranheza aos ouvidos, como em: "Me dá um pedaço de bolo".

A escola pode dedicar-se mais a aspectos gramaticais estigmatizados, como por exemplo na realização da concordância, seja nominal ou verbal, pois está altamente relacionada a fatores socioeconômicos e avaliações negativas. (RAMOS; DUARTE, 2003, p. 91).

O terceiro princípio trata da inserção da variação linguística na matriz social. Nenhuma referência a esse item foi encontrada ao longo do currículo, pois o documento 
não promove reflexões sobre questões da variação, apenas constatações rasas e correções. As variações da língua, especialmente no Brasil, que ocorrem devido às diferenças sociais e econômicas, não são abordadas; o prestígio de alguns falantes e o demérito de outros não é apresentado, nem combatido pelo currículo.

Quanto ao quarto princípio, que se dedica à existência de estilos monitorados para eventos de letramento e estilos mais casuais para situações de oralidade, encontramos algumas aproximações. No tangente ao trabalho de gêneros, o currículo propicia o uso da língua em diferentes situações, a fim de promover situações de letramento e de oralidade. No entanto, restringe as questões de variação linguística a aspectos da oralidade.

O quinto princípio está vinculado a uma análise etnográfica do ambiente escolar e da sala de aula. Mas a proposta de um currículo comum e unificado se dedica ao oposto disso, impõe habilidades específicas e indiferentes às especificidades de cada região, escola ou alunado. Embora não seja o objetivo do currículo elencar particularidades, ele poderia mencionar e evidenciar a necessidade dessas análises etnográficas.

Já o sexto princípio fala da conscientização quanto às desigualdades expressas nos estigmas de algumas variedades linguísticas. Parágrafos que abordam o combate ao preconceito linguístico e a conscientização das variações são encontrados, mesmo que descontextualizados, nos textos introdutórios. Porém, ao analisar as habilidades, não se encontram termos que remetem a uma reflexão do uso da língua, a uma análise crítica das variações, a uma conscientização de onde as variações vêm, das cargas valorativas que carregam. Faltam propostas que promovam o refletir, o repensar e o agir sobre as questões da língua, em especial ao preconceito linguístico e à desigualdade social que ela reflete.

\section{Conclusões}

O currículo traz a variação linguística para seu texto, aborda-o em textos introdutórios. Mas ao destrinchar as habilidades que se propõem na sala de aula, encontra-se uma grande lacuna no que se refere à conscientização dos diferentes falares, da representação social que a variação linguística carrega, do refletir sobre as mudanças linguísticas e do repensar sobre o agir e o avaliar determinadas variedades.

Num primeiro momento, o texto se apresenta de modo satisfatório, mas, ao esquadrinha-lo, faz-se pouco efetivo para uma educação transformadora, a qual promova a igualdade/equidade entre os estudantes, que permita acesso a bens culturais pouco conhecidos. As práticas de sala de aula se apresentam de maneira pouco didática.

O currículo trata a diversidade linguística apenas na comparação com línguas indígenas ou em situação de fronteiras; trata da variação em textos escritos para a adequação e correção; não propõe a superação dos estigmas da língua; não apresenta justificativas para a variação linguística no tocante às desigualdades socioeconômicas; prioriza a variação nos gêneros orais, ignorando a variação em gêneros escritos; aborda tratamento da norma em pontos que não acarretam uma avaliação negativa, não focando os esforços em aspectos mais relevantes. 


\section{REFERÊNCIAS}

BAGNO, M. Dicionário crítico de sociolinguística. São Paulo: Parábola, 2017.

BORTONI-RICARDO S. M. \& DETTONI, R. V. Diversidades Linguísticas e Desigualdades Sociais: Aplicando a Pedagogia Culturalmente Sensível. In: PAGLIARINI, M. I.; ASSIS-PETERSON, A. A. Cenas de Sala de Aula. (p. 81-103). Campinas: Mercado de Letras, 2001.

BORTONI-RICARDO, S. M. Nós cheguemu na escola, e agora? - sociolinguística \& educação. São Paulo: Parábola Editorial, 2005.

BRASIL. Base Nacional Comum Curricular. 2017. Disponível em: < http://basenacionalcomum.mec.gov.br/> Acesso em: 20/01/2019.

FARACO, C. A. Norma culta brasileira: desatando alguns nós. São Paulo: Parábola Editorial, 2008.

GANDIN, L. A., DINIZ-PEREIRA, J. E. \& HYPOLITO, A. M. Para além de uma educação multicultural: teoria racial crítica, pedagogia culturalmente relevante e formação docente (entrevista com a professora Gloria Ladson-Billings). Revista Educação \& Sociedade. Campinas, nº 79, p 275 - 293, 2002.

GERALDI, J. W. Concepções de linguagem e ensino de português. In: GERALDI, J. W. O texto na sala de aula. São Paulo: Editora Ática, 2000.

LADSON-BILLINGS, G. But that's just good teaching! The case for Culturally Relevant Pedagogy. In: Theory into practice. The Ohio State University. Vol 34, nº 3, p. $159-166,1995$.

LAPERUTA-MARTINS, M. A sociolinguística e o ensino de língua portuguesa - uma proposta para um ensino aprendizagem livre de preconceitos. (Tese de Doutorado). Universidade Estadual Paulista, Araraquara, 2014.

LOPES, A. C., \& Macedo, E. Teorias de Currículo. São Paulo: Cortez, 2011.

SEVERINO, J. A. Metodologia do trabalho científico. São Paulo: Cortez, 2016.

Recebido em: junho de 2020.

Aprovado em: setembro de 2020.

Como citar este trabalho:

ZWIRTES, P.; MARTINS, M. L. Língua portuguesa da Base Nacional Comum Curricular (2017): uma análise sob a ótica da Sociolinguística Educacional. Traços de Linguagem. v. 4, n. 2, p. 51-63, 2020. 